\title{
Elimination of central sleep apnoea by mitral valvuloplasty: the role of feedback delay in periodic breathing
}

\author{
A E Rubin, S H Gottlieb, A R Gold, A R Schwartz, P L Smith
}

Thorax 2004;59:174-176. doi: 10.1136/thx.2003.007799

Central sleep apnoea is a form of periodic breathing which resembles Cheyne-Stokes respiration but occurs only during sleep. One mechanism in the pathogenesis is a delay in chemical feedback from the lungs to the medullary respiratory centre. We explored the relationship between circulatory feedback delay in a patient with central sleep apnoea and Cheyne-Stokes respiration before and after mitral valve repair. Preoperatively the patient had severe central sleep apnoea and an increased circulation time. Following mitral valvuloplasty the circulation time was decreased with resolution of central sleep apnoea. This case demonstrates the role of feedback delay in central sleep apnoea and suggests that similar haemodynamic mechanisms may lead to central sleep apnoea and Cheyne-Stokes respiration.

$\mathrm{P}$ eriodic breathing was first associated with severe heart failure by Stokes in the early 19th century. ${ }^{1}$ Subsequent investigators suggested that a delay in chemical feedback to the medullary respiratory centre was a major cause for the pattern of periodic breathing now known as Cheyne-Stokes respiration. ${ }^{23}$ Central sleep apnoea is characterised by respiration that starts and stops abruptly without significant variability in its frequency and depth, ${ }^{4}$ while Cheyne-Stokes respiration is characterised by a sinusoidal pattern in the frequency and depth of respiration. ${ }^{5}$ The mechanism of central sleep apnoea may be similar to that of Cheyne-Stokes respiration and be caused by a delay in chemical feedback to the medullary respiratory centre. ${ }^{4}$ This report describes a patient with central sleep apnoea, mitral regurgitation with reduced cardiac index, and a markedly prolonged arm to tongue circulation time that was corrected by mitral valvuloplasty.

\section{CASE REPORT}

A 64 year old man in whom a heart murmur had been noted since the age of 19 remained well until the age of 63 when he complained of progressive dyspnoea on exertion, fatigue, sleepiness, and weight loss. On physical examination the patient's height was $175 \mathrm{~cm}$ and his weight was $63 \mathrm{~kg}$. His blood pressure was $160 / 80 \mathrm{~mm} \mathrm{Hg}$ with an irregular pulse of 84 per minute and regular respirations of 18 per minute. A precordial heave was noted and a grade $3 / 6$ systolic murmur was heard at the apex with radiation to the axilla.

Laboratory data included an electrocardiogram which demonstrated atrial fibrillation and left ventricular hypertrophy. Cardiomegaly was evident on chest radiography. Two dimensional echocardiography revealed a thickened mitral valve $(0.8 \mathrm{~cm})$ and a flail anterior mitral leaflet. The left atrium was markedly enlarged with a diameter of $7 \mathrm{~cm}$. The left ventricle was thick $(1.5 \mathrm{~cm})$ and moderately dilated $(6.5 \mathrm{~cm})$ with rapid early diastolic filling and a fractional shortening of $32-47 \%$. Cardiac catheter-isation showed normal coronary arteries and confirmed gross mitral regurgitation with reflux of dye into the pulmonary veins and increased pulmonary capillary wedge pressure (V waves $=40 \mathrm{~mm} \mathrm{Hg}$, mean PA pressure $=20 \mathrm{~mm} \mathrm{Hg}$ ). A sleep study was performed using standard techniques as previously described. ${ }^{6}$ The patient had recurrent apnoea and hypopnoeas (apnoea/hypopnoea index (AHI)) at a rate of 54 per hour with a mean event duration of 30 (9) seconds (table 1 ); $61 \%$ of the events were central, $29 \%$ were mixed, and $10 \%$ were obstructive (fig 1). Mean baseline oxyhaemoglobin saturation was $98 \%$ and fell to a mean low of $93 \%$ during events. A second full night sleep study was performed with oxygen supplementation at a flow rate of $4 \mathrm{l} / \mathrm{mm}$ via nasal cannulae. Central and mixed disordered breathing events were seen with a $45 \%$ reduction in AHI and a slight increase in event duration (table 1). The circulation time from the arm to the tongue was determined by injection into the right antecubital vein of $400 \mathrm{mg}$ magnesium sulfate diluted to $100 \mathrm{mg} / \mathrm{ml}$ as described by Friedberg. ${ }^{7}$ The patient's mean (SD) arm to tongue circulation time was 50.9 (3.7) seconds which was much longer than the arm to tongue circulation time of 19.3 (1.9) seconds measured in two healthy subjects.

After mitral valvuloplasty the patient noted marked improvement in his sleep, daytime hypersomnolence, dyspnoea and fatigue, and a weight gain of $10 \mathrm{~kg}$. An echocardiogram showed normal mitral valve motion and a low normal left ventricular ejection fraction (45-50\%). The cardiac index by thermodilution improved from $1.4 \mathrm{l} / \mathrm{min} / \mathrm{m}^{2}$ immediately before the operation to $2.4 \mathrm{l} / \mathrm{min} / \mathrm{m}^{2}$ immediately afterwards. The mean (SD) arm to tongue circulation time decreased to 29.2 (1.7) seconds. Two months after the operation a sleep study showed complete resolution of the previously documented sleep apnoea (table 1).

\section{DISCUSSION}

This case highlights the relationship between circulation time and central sleep apnoea. Our patient had central sleep apnoea in association with increased circulation time, both of which improved after mitral valvuloplasty. The patient's response suggests that circulation time plays a major role in the pathogenesis of central sleep apnoea.

In biological systems, periodic breathing may be produced by either altered chemosensitivity of the respiratory centre (controller gain), decreased oxygen stores, or by delayed chemical feedback $\left(\mathrm{CO}_{2}\right.$ and $\left.\mathrm{O}_{2}\right)$ from the blood in the lungs to the respiratory centres in the central nervous system (feedback delay). ${ }^{3}$ The circulation time is a function of both cardiac output and blood volume: circulation time $=$ blood volume/cardiac output. ${ }^{7}$ With the development of mitral regurgitation in our patient, a prolonged circulation time could have been caused by both increased blood volume from atrial enlargement and reduced forward cardiac output.

Previous studies have linked periodic breathing (CheyneStokes respiration) with increased circulation time in 
Table 1 Sleep parameters

\begin{tabular}{|c|c|c|c|c|c|c|c|}
\hline & \multirow{2}{*}{$\begin{array}{l}\text { Total sleep } \\
\text { time (min) }\end{array}$} & \multicolumn{3}{|c|}{$\begin{array}{l}\text { Apnoea/hypopnoea index (AHI) (apnoeas + } \\
\text { hypopnoeas/h sleep)* }\end{array}$} & \multirow{2}{*}{$\begin{array}{l}\text { Apnoea duration } \\
\text { (s) }\end{array}$} & \multirow{2}{*}{$\begin{array}{l}\text { Baseline } \mathrm{SaO}_{2} \\
(\%) \dagger\end{array}$} & \multirow{2}{*}{$\begin{array}{l}\text { Mean low Sao } \\
(\%) \ddagger\end{array}$} \\
\hline & & Central & Mixed & Obstructed & & & \\
\hline Study 1: baseline & 228 & 34 & 15 & 5 & $30(9)$ & $98(1.6)$ & $93(1.8)$ \\
\hline Study 2 : breathing $\mathrm{O}_{2}$ & 157 & 8 & 15 & 7 & $34(9)$ & $98(1.0)$ & $96(1.9)$ \\
\hline Study 3: after mitral valvuloplasty & 273 & 0 & 0 & 0 & - & 96 & \\
\hline
\end{tabular}

*Non-REM sleep.

tInitial baseline value only.

$\mp$ Minimum $\mathrm{SaO}_{2}$ in the absence of apnoea.
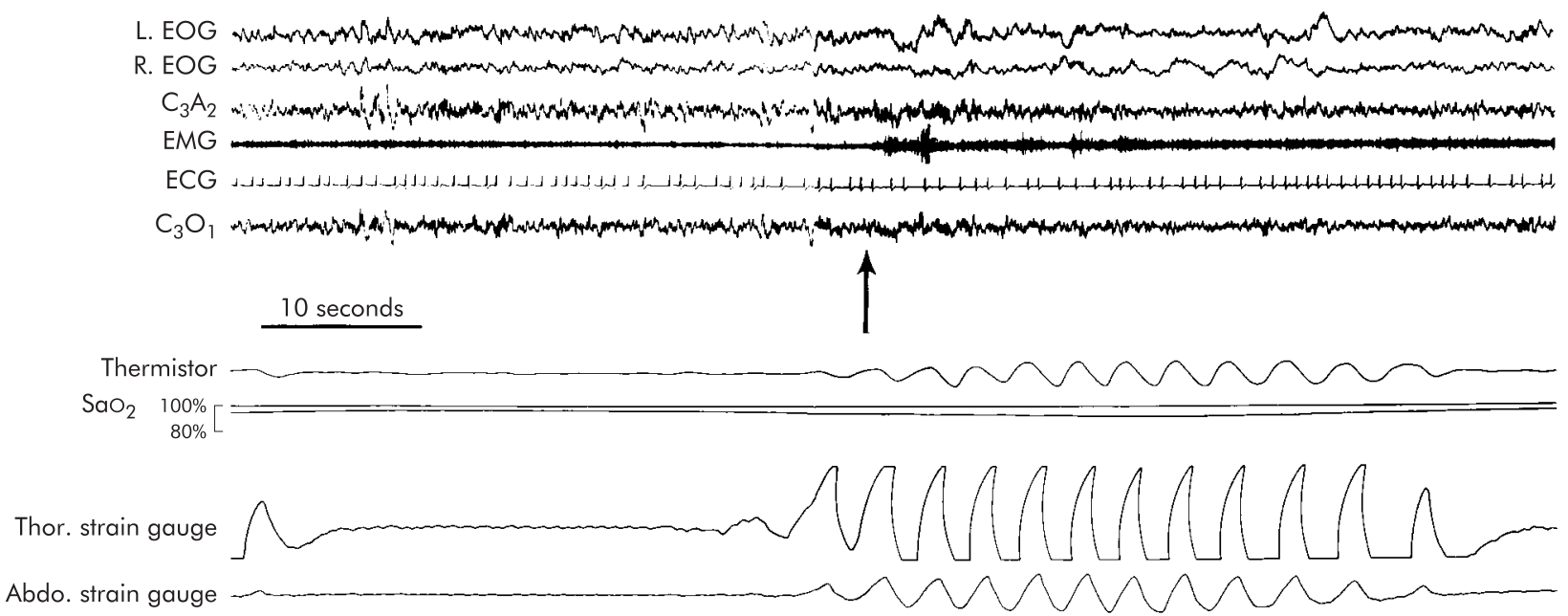

Figure 1 A 35 second central apnoea followed by an arousal (arrow) and a 37 second ventilatory phase. The prolonged circulation time is reflected in the fall in oxyhaemoglobin saturation persisting long after the onset of breathing. The artefact in the thoracic tracing is caused by the patient's hyperdynamic precordium.

patients with congestive heart failure. ${ }^{2}{ }^{8}$ In fact, clinical data have indicated similar prolongation of circulation time (3054 seconds) in patients with congestive heart failure and Cheyne-Stokes respiration to that observed in our patient preoperatively. Periodic breathing can be induced by lengthening the circulation time in animals. ${ }^{3}$ In patients with congestive heart failure and Cheyne-Stokes respiration, cycle lengths were observed that were twice the lung to brain circulation time. ${ }^{8}$ Our patient had a similar $2: 1$ ratio with a cycle length of 70 seconds and a lung to artery circulation time of approximately 36 seconds (estimating a vein to lung time of 15 seconds in severe congestive heart failure from the data of Pryor ${ }^{2}$ and of Lange and Hecht ${ }^{8}$ ). Following correction of our patient's severe mitral regurgitation, the circulation time decreased markedly and periodic breathing during sleep resolved completely.

In addition to feedback delay, periodic breathing may also be caused by altered respiratory centre chemosensitivity (controller gain). For a given circulation time, an increase in the chemosensitivity of the respiratory control centres results in an increase in the tendency for breathing to oscillate. ${ }^{5}$ Although we did not measure oxygen chemosensitivity, previous studies have shown that supplemental oxygen decreases central sleep apnoea by decreasing the controller gain of the respiratory centre..$^{-11}$ Our finding that the apnoea/ hypopnoea index decreased markedly on oxygen is consistent with the notion that a concomitant increase in controller gain also has a role in the pathogenesis of periodic breathing. Nevertheless, improvement in hypoxia while the circulation time remained prolonged did not eliminate sleep apnoea, which suggests that a prolonged circulation time played a major role in the pathogenesis of sleep apnoea in our patient.

This case report demonstrates the elimination of central sleep apnoea by a reduction in circulation time from markedly prolonged levels to near normal levels following surgical correction of severe mitral regurgitation. It highlights the similarity between the mechanism of central sleep apnoea and that of Cheyne-Stokes respiration. Our findings suggest that central sleep apnoea may be responsible for the sleep complaints in patients with congestive heart failure, including paroxysmal nocturnal dyspnoea. ${ }^{12}$

\section{Authors' affiliations}

A E Rubin, A R Schwartz, P L Smith, Department of Medicine, Division of Pulmonary and Critical Care Medicine, Johns Hopkins University School of Medicine, Baltimore, MD, USA

S H Gottlieb, Division of Cardiology, Johns Hopkins University School of Medicine, Baltimore, MD, USA

A R Gold, Division of Pulmonary - Critical Care Medicine, DVA Medical Center, Northpoint, NY and SUNY at Stony Brook School of Medicine, USA

Correspondence to: Dr P L Smith, Room 4B67, Johns Hopkins Asthma and Allergy Center, 5501 Hopkins Bayview Circle, Baltimore, MD 21224, USA; plsmith@jhmi.edu

Received 31 March 2003

Accepted 11 May 2003

\section{REFERENCES}

1 Stokes W. Diseases of the heart and aorta. Dublin: Hodges and Smith, 1854:324-5. 
2 Pryor WW. Cheyne-Stokes respiration in patients with cardiac enlargement and prolonged circulation time. Circulation 1951;4:233-8

3 Guyton AC, Cromwell JW, Moore JE. Basic oscillating mechanism of CheyneStokes breathing. Am J Physiol 1956;1887:395-8.

4 White DP. Central sleep apnea. Med Clin North Am 1985:69:1205-19.

5 Cherniack NS, Longobardo GS. Cheyne-Stokes breathing. An instability in physiologic control. N Engl J Med 1973;288:952-7.

6 Smith PL, Haponik EF, Bleecker ER. The effects of oxygen in patients with sleep apnea. Am Rev Respir Dis 1984;130:958-63.

7 Friedberg C. Disease of the heart. Philadelphia: WB Saunders, 1966:314-7.

8 Lange RL, Hecht HH. The mechanisms of Cheyne-Stokes respiration. J Clin Invest 1962;41:42-52.
9 Skatrud JB, Dempsey JA, Iber $\mathrm{C}$, et al. Correction of $\mathrm{CO}_{2}$ retention during sleep in patients with chronic obstructive pulmonary diseases. Am Rev Respir Dis $1981 ; 124: 260-8$.

10 Berssenbrugge A, Dempsey J, Iber C, et al. Mechanisms of hypoxiainduced periodic breathing during sleep in humans. J Physiol 1983;343:507-24.

11 Gold AR, Bleecker ER, Smith PL. A shift from central and mixed sleep apnea to obstructive sleep apnea resulting from low-flow oxygen. Am Rev Respir Dis 1985; 132:220-3.

12 Harrison TR, King CE, Calhoun JA, et al. Cheyne-Stokes respiration as the cause of paroxysmal dyspnea at the onset of sleep. Arch Intern Med 1934;53:891-910.

\section{Clinical Evidence - Call for contributors}

Clinical Evidence is a regularly updated evidence based journal available worldwide both as a paper version and on the internet. Clinical Evidence needs to recruit a number of new contributors. Contributors are health care professionals or epidemiologists with experience in evidence based medicine and the ability to write in a concise and structured way.

\section{Currently, we are interested in finding contributors with an interest in} the following clinical areas:

Altitude sickness; Autism; Basal cell carcinoma; Breast feeding; Carbon monoxide poisoning; Cervical cancer; Cystic fibrosis; Ectopic pregnancy; Grief/bereavement; Halitosis; Hodgkins disease; Infectious mononucleosis (glandular fever); Kidney stones; Malignant melanoma (metastatic); Mesothelioma; Myeloma; Ovarian cyst; Pancreatitis (acute); Pancreatitis (chronic); Polymyalgia rheumatica; Post-partum haemorrhage; Pulmonary embolism; Recurrent miscarriage; Repetitive strain injury; Scoliosis; Seasonal affective disorder; Squint; Systemic lupus erythematosus; Testicular cancer; Varicocele; Viral meningitis; Vitiligo

However, we are always looking for others, so do not let this list discourage you.

\section{Being a contributor involves:}

- Appraising the results of literature searches (performed by our Information Specialists) to identify high quality evidence for inclusion in the journal.

- Writing to a highly structured template (about 2000-3000 words), using evidence from selected studies, within 6-8 weeks of receiving the literature search results.

- Working with Clinical Evidence Editors to ensure that the text meets rigorous epidemiological and style standards.

- Updating the text every eight months to incorporate new evidence.

- Expanding the topic to include new questions once every 12-18 months.

If you would like to become a contributor for Clinical Evidence or require more information about what this involves please send your contact details and a copy of your CV, clearly stating the clinical area you are interested in, to Claire Folkes (cfolkes@bmigroup.com).

\section{Call for peer reviewers}

Clinical Evidence also needs to recruit a number of new peer reviewers specifically with an interest in the clinical areas stated above, and also others related to general practice. Peer reviewers are health care professionals or epidemiologists with experience in evidence based medicine. As a peer reviewer you would be asked for your views on the clinical relevance, validity, and accessibility of specific topics within the journal, and their usefulness to the intended audience (international generalists and health care professionals, possibly with limited statistical knowledge). Topics are usually 2000-3000 words in length and we would ask you to review between 2-5 topics per year. The peer review process takes place throughout the year, and our turnaround time for each review is ideally 10-14 days.

If you are interested in becoming a peer reviewer for Clinical Evidence, please complete the peer review questionnaire at www.clinicalevidence.com or contact Claire Folkes(cfolkes@bmigroup.com). 